Fi ne st ruct ural study of a cerebral tunor char act eri zed by a honeyconb appear ance after a 20-year post-nortem i nt erval

\begin{tabular}{|l|l|}
\hline 著者 & $\begin{array}{l}\text { KUBOTA Toshi hi ko, H RANO Asao, TANAKA Ryui chi , } \\
\text { TAKAHASH H t oshi }\end{array}$ \\
\hline $\begin{array}{l}\text { j our nal or } \\
\text { publ i cat i on } \mathrm{ti} \text { tl e }\end{array}$ & Neur opat hol ogy \\
\hline vol une & 26 \\
\hline number & 2 \\
\hline page $\mathrm{r}$ ange & $158-160$ \\
\hline year & $2006-04$ \\
\hline URL & ht t p: //hdl . handl e. net /10098/1796 \\
\hline
\end{tabular}


Neuropathology Education

\section{Fine Structural Study of A Cerebral Tumor Characterized by Honeycomb Appearance After 20 Years Postmortem Interval}

Toshihiko Kubota ${ }^{1}$, Asao Hirano ${ }^{2}$, Ryuichi Tanaka ${ }^{3}$ and Hitoshi Takahashi $^{4}$

${ }^{1}$ Department of Neurosurgery, Faculty of Medical Sciences, University of Fukui, Fukui, Japan, 2Division of Neuropathology, Department of Pathology, Montefiole Medical Center, Albert Einstein Medical College, New York, USA, ${ }^{3}$ Department of Neurosurgery, Brain Research Institute, Niigata University, Niigata, Japan and ${ }^{4}$ Department of Pathology, Brain Research Institute, Niigata University, Niigata, Japan

Correspondence: Toshihiko Kubota,M.D. Department of Neurosurgery, Faculty of Medical Sciences, University of Fukui, 23-3 Shimoaizuki, Matsuoka-Cho, Yoshida-Gun, Fukui, 910-1193 Japan TEL:81-776-61-3111, FAX:81-776-61-8115

E-mail: tkubott@fmsrsa.fukui.med.ac.jp 


\section{CLINICAL HISTORY}

The patient was a 24-year-old man who had experienced morning headaches, nausea and a gradually progressive left sided motor disturbance for 2 weeks until he was admitted to Niigata University Hospital. His past and family histories were non-contributory.

On admission, he was alert and well oriented. Slightly choked discs, left sided hemiparesis and sensory deficits were observed. Pneumoencephalographic and angiographic findings revealed a right fronto-parietal tumor. He underwent a craniotomy on the $29^{\text {th }}$ January 1956. After the dura was opened, swollen and discolored frontal gyri were exposed. Under the cortex, a large cyst was found. The cyst contained $75 \mathrm{ml}$ coffee-colored fluid suggestive of old hemorrhage. The cyst wall and the surrounding tumor-like tissue were macroscopically totally removed. The neuropathological diagnosis was oligodendroglioma. He was given 50Gy cobalt irradiation after the operation.

Six months after his discharge, the patient suddenly suffered left sided hemiconvulsion. He was bedridden for about 5 years. However, over the next 10 years, he could walk with left sided hemiparesis on anticonvulsant administration. The patient enjoyed his life taking care of carp cultivation. Again, the patient complained of headache and nausea, and became bedridden 6 months before he succumbed to the disease. The patient gradually suffered from blindness, deafness, drowsiness and urinary incontinence, resulting in death. The total clinical course was 16 years.

\section{GROSS AND MICROSCOPIC FINDINGS}

There was a large skull bone defect, $10 \times 10 \mathrm{~cm}$ in diameter, due to a decompression maneuver in the right fronto-parietal region. The fixed brain weighed $1570 \mathrm{~g}$. Marked cerebral swelling was noted. The right cerebral hemisphere showed a superficial spherical mass which bulged into the decompressed skull bone defect at the fronto-parietal lobe. 
The cut surface showed a huge, $7.0 \times 7.5 \mathrm{~cm}$, sharply demarcated rubbery firm mass occupying the right centrum semiovale and cortices of the right frontal and parietal lobe (Fig1). The mass markedly compressed the right lateral ventricle. Marked increased intracranial pressure was manifested by bilateral temporal pits and right hippocampal herniation as well as flattened gyri, narrow sulci and increased volume of the cerebrum. Additionally, obvious degeneration of the bilateral optic nerves, chiasm and lateral geniculate bodies. There was secondary degeneration of the right corticospinal tract below the level of the cerebral peduncle and atrophy of the pyramidal tract in the spinal cord on the left side. There were no disseminated lesions on the surface of central nervous system and metastases in the general organs including lymph nodes.

Microscopically, the mass was a highly cellular tumor consisting of compactly arranged monotonous cells with oval central nuclei and clear or pale eosinophilic cytoplasm (Fig.2). Honeycomb appearance was immediately recognized by seeing the collection of tumor cells with perinuclear halo. Infrequent bizarre nuclei and rare mitotic figures were observed. The cell sheets were intersected by vascular stroma and amorphous mucinous collections. The tumor margin was clearly demarcated from the surrounding normal tissue. Neither rosette formation nor perivascular pseudorosettes were evident. Some cells were positive for GFAP ; they were reminiscent of the minigemistocyte observed in oligodendroglioma (Fig.3). The tumor cells were negative for neuronal markers ( neurofilament, synaptophysin, chromogranin A, $\beta$-tubulin, NeuN, MBP, A2B5) and for EMA, cytokeratin and vimentin. Ki-67 staining index was less than $1 \%$. Antigen retrieval for EMA immunostaining was performed ${ }^{1}$. There was no EMA positive dots in this tumor.

The specimen for electron microscopic observation was obtained from formalin-fixed tumor tissue after 20 years postmortem interval. The fine structure occasionally revealed microrosettes consisting of numerous interdigitating microvilli, basal bodies and prominent long intercellular junctions (Fig.4). These fine structural features are characteristic of ependymoma. 


\section{DIAGNOSIS}

Clear cell ependymoma

\section{DISCUSSION}

Central nervous system(CNS) neoplasms consisting of cells with clear cytoplasm and uniform, round nuclei are histologically diagnosed as oligodendroglioma commonly because of their resemblance to normal oligodendrocytes under light microscopic observation. Oligodendrocytes are central-myelin-forming cells. They have numerous long cell processes that wrap around axons under electron microscopic observation ${ }^{2}$. Images of oligodendroglia

under light microscopy show severe artifactual change manifested by clear small-sized cytoplasm.

Reports have shown that clear cell tumors are not restricted to oligodendroglioma, but can be seen in CNS tumors of different origin $^{3}$. There are various CNS neuroepithelial neoplasms with clear cell features, such as clear cell ependymoma ${ }^{4}$, central neurocytoma ${ }^{5}$, dysembryoplastic neuroepithelial tumor, mixed neuronal-glial tumor 6 . Their diagnoses were supported by electron microscopic studies and immunohistochemical investigations ${ }^{7}$. Clear cell ependymoma often lacks classical ependymoma features such as rosettes, perivascular pseudorosettes and ependymal cell lining, which can be distinguished by light microscopy ${ }^{8}$. The tumor cells may be not immunoreactive for GFAP. The clear cell ependymoma has been demonstrated to have fine structural features such as microrosettes, microvilli, cilia, basal bodies and prominent long junctional complexes ${ }^{3,4,7,8}$.

In the present case, the tumor consisted of monotonous clear cells with no specific features. Immunohistochemical study demonstrated some GFAP-positive minigemistocytic cells. It had been diagnosed as a typical oligodendroglioma. However, examination of the formalin-fixed autopsy material by electron microscopy revealed the structures of microrosettes, basal bodies and junctional complexes consistent with clear cell ependymoma. 


\section{ACKNOWLEDGMENTS}

The authors thanks Dr. Josefina Jlena for her valuable suggestions.

\section{REFERENCES}

1. Kawano N, Yasui Y, Utsuki S, Oka H, Fujii K, Yamashina S. Light microscopic demonstration of the microlumen of ependymoma : a study of the usefulness of antigen retrieval for epithelial membrane antigen(EMA) immunostaining. Brain Tumor Pathol 2004:21:17-21

2.Hirano A. Confirmation of the oligodendroglial origin of myelin in the rat. J Cell Biol 1968; 38:637-640.

3.Kubota T, Hayashi M, Kawano H, Kabuto M, Ishise J. Differential diagnosis of oligodendrogliomas:Immunohistochemical and ultrastructural study. Brain Tumor Pathol 1991; 8:17-24

4. Kawano N, Yada K, Aihara M, Yagishita S. Oligodendrogliomalike cells ( clear cells ) in epnedymoma. Acta

Neuropathol(Berl) 1983; 62:141-144

5. Kubota T, Hayashi M, Kawano H et al. Central neurocytoma : immunohistochemical and ultrastructural study. Acta Neuropathol 1991;81:418-427

6. Takeuchi H, Kubota T, Sato K, Yao Y, Kitai R, Arishima H. Atypical neuronal-glial tumors of cerebral hemispheres in adult with PNET-like component: clinicopathological features of 5 cases. Clin Neuropathol 2003; 22:47-56

7. Cenacchi G, Giangaspero F, Cerasoli S, Manetto V, Martinelli GN. Ultrastructural characterization of oligodendroglial-like cells in central nervous system tumors. Ultrastruct Pathol $1996 ; 20: 537-547$

8.Min K-W, Scheithhauer BW. Clear cell ependymoma: A mimic of oligodendroglioma: Clinicopathologic and ultrastructural considerations. Amer J Surg Pathol 1997; 21:820-826 


\section{FIGURE LEGEND}

Fig. 1 : Coronal section at the level of the midbrain, showing a huge well demarcated tumor mass $($ bar $=1 \mathrm{~cm})$.

Fig.2 : Compactly arranged tumor cells show spheroidal nuclei, and perinuclear cytoplasmic halo with delicate cytoplasmic membrane. (HE stain, bar $=50 \mu \mathrm{m}$ )

Fig.3 : Tumor cells immunopositive for GFAP are seen. ( GFAP immunoperoxidase stain, bar $=50 \mu \mathrm{m}$ ).

Fig.4 : Electron micrograph showing a microrosette consisting of numerous microvilli and an associated long junctional complex. X 27,000 
Fig.1

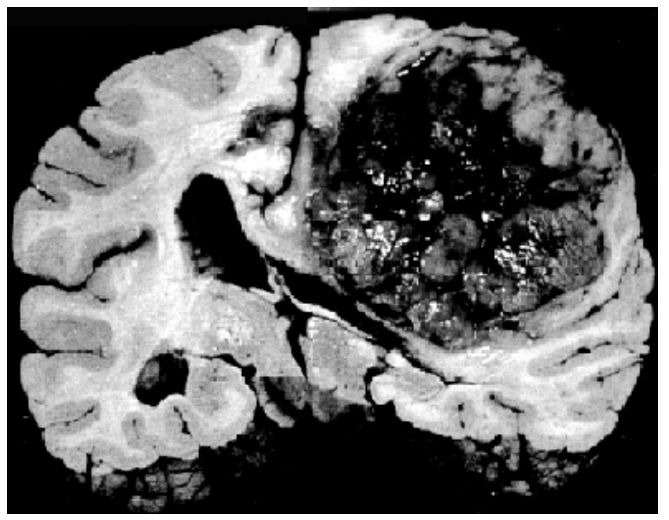

Fig.2

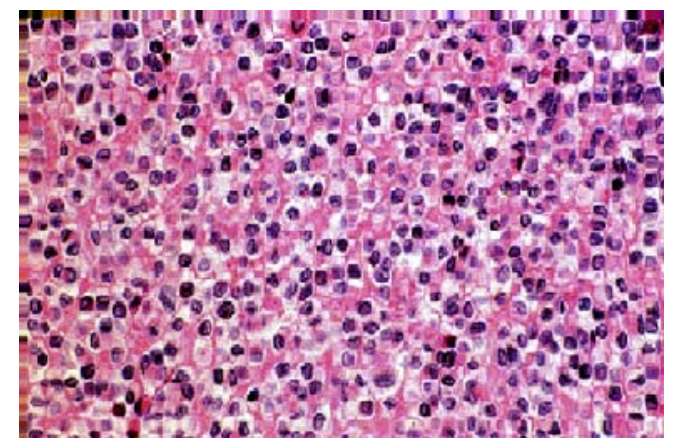

Fig.3

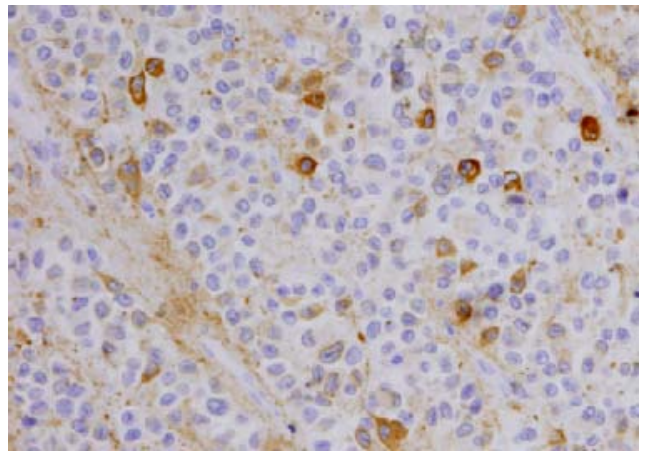

Fig.4

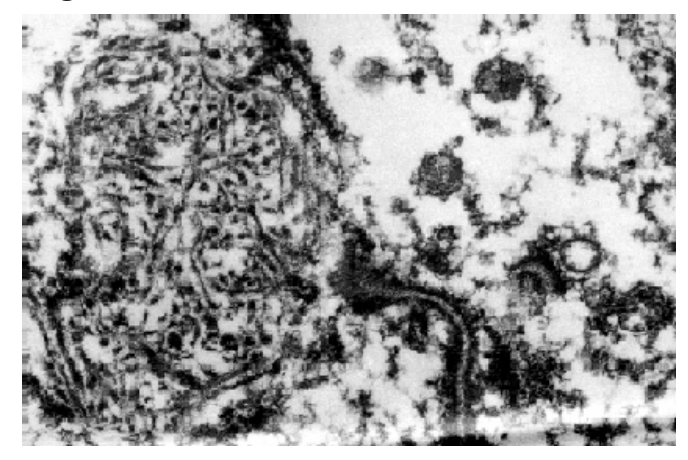

